\title{
Blogs como espaços de conversação: interações conversacionais na comunidade de blogs insanus ${ }^{1}$
}

\author{
Alex Primo \\ Universidade Federal do Rio Grande do Sul \\ alex.primo@terra.com.br \\ Ana Maria Reczek Smaniotto3 \\ Universidade Federal do Rio Grande do Sul
}

\begin{abstract}
Resumo: O blog não passa de um diário íntimo na Web? Como conversam os participantes de um blog? A partir dessas questões, este artigo discute a conversação na comunidade de blogs insanus (http://www.insanus.org). Para tanto, busca definições de conversação e compara os procedimentos utilizados para estudá-la em encontros face-a-face e em processos mediados por computador. A partir disso, discute a especificidade da conversação em blogs, revisando recursos tecnológicos que viabilizam tal processo interativo. Finalmente, analisa uma conversação que percorreu vários blogs daquela comunidade.
\end{abstract}

Palavras-chave: Blog; conversação; comunidade virtual; interação

Abstract: A blog is just a personal journal on the Web? How do the participants of a blog dialogue? Taking these questions into consideration, this paper discusses conversational process in the blog community insanus (http://www.insanus.org). With this objective, it analyzes definitions of converstation and compares the methods used to stydy it in face-to-face encounters and in computer mediated processes. Then, it discusses the singularity of conversations in blogs, reviewing technological resources that mediate those interactive processes. Finally, the paper analyzes one conversation that transversed several blogs of that community.

Keywords: Blog; conversation; virtual community; interaction

\footnotetext{
${ }^{1}$ Trabalho apresentado ao NP-08 - Núcleo de Estudo de Tecnologias Informacionais da Comunicação - do V Encontro dos Núcleos de Pesquisa Intercomdo, na XXVIII INTERCOM, na ECO- UERJ, Rio de Janeiro, em setembro de 2005. Este artigo contou com o financiamento das agências CNPq e Fapergs.

${ }_{2}^{2}$ Doutor em Informática na Educação (PGIE/UFRGS), mestre em Jornalismo (Ball State University) e professor do PPGCOM/UFRGS. Coordenador do Laboratório de Interação Mediada por Computador (http://www.ufrgs.br/limc)

3 Acadêmica da Fabico/UFRGS, Bolsista de iniciação científica PIBIC/CNPq.
} 
Resumen: El blog no es más que um diario íntimo en la web? Como mantienen conversación los participantes en la Web? A partir de esas preguntas, este artículo discute la conversación en la comunidad de blogs insanus (http://www.insanus.org). Para eso, busca definiciones de conversación y compara los procedimientos utilizados para estudiarla en encuentros cara-a-cara y en procesos mediados por computador. En continuación, discute la especificidad de la conversación en blogs, revisando recursos tecnológicos que viabilizan tal proceso interactivo. Finalmente, analiza una conversación que ha recorrido varios blogs de aquella comunidad.

Palabras-clave: Blog; conversación; comunidad virtual; interacción

Résumé: Le blog ne passe pas d'un journal intime dans la web? Comme parlent les participants d'un blog? A partir des ces questions cette article discute la conversation dans la communité des blogs insanus (http://www.insanus.org.). Pour cette raison, cherche definitions de conversation et fait la comparison de les procediments utilisées pour le étudier dans le rencontre tête-a-tête et dans les process avec intermediation de l'ordinateur. En suivant, discut l'especifité de la parole dans les blogs, pendant on fait la revision de les resources tecnologiques que vient viabilizer cette procès interative. Finalement, fait une analyse d'une conversation que a percorru plusieurs blogs de cette communité.

Most-clés: Blog; conversation; communauté virtuelle; interaction

\section{Introdução}

Os blogs vêm sendo com grande freqüência comparados a diários íntimos. Contudo, ao observar-se com maior cuidado os textos e interações que singularizam blogs e diários em papel, pode-se logo perceber que aquela analogia apresenta problemas. Este artigo, por outro lado, pretende discutir os blogs como espaços de conversação. Ao investigar-se as interações que emergem nos blogs e entre eles o foco precisa ampliar-se, devendo-se observar não apenas os chamados "blogueiros" ou "donos" do blog mas também todos os outros interagentes que manifestam-se nas janelas de comentários e/ou criam links para aqueles blogs. 
Este trabalho faz uma revisão da especificidade das conversações em ambientes mediados por computador, para mais tarde discutir como se dão as interações dialogais em e entre blogs. A partir desse levantamento teórico, uma observação empírica de um processo conversacional ocorrido na comunidade 4 de blogs insanus (http://www.insanus.org) é analisada.

\section{Da conversação face-a-face à conversação mediada pelo computador}

A conversação é "a prática social mais comum no dia-a-dia do ser humano", a primeira forma de linguagem a que somos expostos e aquela que jamais abandonamos no curso da vida (Marcuschi, 2001, p. 5). A conversação, no entanto, é estudada de formas bastante distintas. Alguns pesquisadores preferem defini-la de forma restrita, enquanto outros com maior amplitude.

O sociólogo Simmel (2000) considera que a conversação é o instrumento mais extenso de toda vida humana em comum. O autor vai estudá-la como uma forma pura de sociabilidade, em que a fala é um fim em si mesmo. O conteúdo é um condutor indispensável daquela estimulação. Isso não quer dizer que ele seja irrelevante, já que o conteúdo precisa ser interessante e mesmo significativo. A diferença é que não se está buscando resultados objetivos, o que cairia fora da conversação. Assim que a discussão ganhe um tom administrativo, de negócios, ela deixa de ser sociável, tendo como foco a confirmação de verdades. Já na conversação, o fato de algo dito ser aceito não é um fim em si, mas uma forma de manter a vivacidade da relação, o entendimento mútuo e o sentimento de grupo.

Goffman (1983), no entanto, vai estudar a conversação de uma forma ampla, como um equivalente de encontro falado. Na verdade, tanto nos estudos desse autor, quanto na tradição da Análise da Conversação o foco recarrai nas interações orais (sem desprezar os signos não-lingüísticos) em encontros presenciais ou mediados por telefone.

As pesquisas em Análise da Conversação tiveram início na década de 60, com raízes na etnometodologia e na antropologia cognitiva. Conforme Marcuschi (2001, p. 6), a preocupação inicial era com a "organização estrutural

\footnotetext{
4 As características comunitárias da rede insanus serão discutidas em um próximo artigos.
} 
convencionalizada ou institucionalizada" da ação e interação social. O autor observa, no entanto, que a Análise da Conversação posteriormente voltou-se para os processos cooperativos na atividade conversacional. Com esse objetivos, procura-se estudar as trocas de turnos, os silêncios e lacunas, as falas simultâneas, as regras conversacionais, a coerência conversacional.

A Análise da Conversação dedica-se às interações orais com identidade temporal, já que "a conversação, mesmo que se dê em espaços diversos (no caso da conversação telefônica), deve ocorrer durante o mesmo tempo" (Marcuschi, 2001, p. 6). Com esse intuito, dá grande ênfase aos procedimentos de registro (gravação e transcrição) das interações espontâneas em situações cotidianas ${ }^{5}$ (Charaudeau e Maingueneau, 2004).

Mas, se o compartilhamento do mesmo contexto temporal é fundamental, como fica o estudo da conversações mediadas por computador? Com exceção de alguns recursos digitais como transmissão de voz e mesmo vídeo em tempo real (como vídeoconferência ou através de programas de "voz sobre IP"), as interações no ciberespaço se dão normalmente através da escrita. Uma importante parcela desses processos comunicativos acontece de forma assíncrona, como em e-mails, listas de discussão e fóruns. O mesmo ocorre com os blogs, objeto deste estudo, e mesmo nos fotoblogs (ou simplesmente flogs), onde os intercâmbios lingüísiticos ocorrem também via escrita. Ora, não se pode supor que nos blogs os interagentes não conversem pelo fato de não haver interações síncronas e através da voz e pela quantidade bastante inferior de pistas não-verbais (o que não quer dizer, claro, que elas não existam).

Se Análise da Conversação dedica-se principalmente ao estudo da alternância de turnos no decorrer do tempo e da coerência conversacional, como tais fenômenos se atualizam na conversação escrita no ciberespaço? Herring (1999) observa que as trocas interativas na comunicação mediada por computador tem menor costura interna em comparação com os intercâmbios face-a-face. Ou seja, com freqüência as respostas são veiculadas distantes dos turnos a que se referem, os tópicos tendem a se degradar com rapidez e múltiplas mensagens tendem a se

5 Logo, peças teatrais e romances não interessam. 
sobrepor (apesar da diferença de tópicos). A autora não deixa de recordar algumas características da comunicação mediada por computador normalmente citadas como “obstáculos” à organização da interação: a falta de feedback não-verbal, o fato de que as mensagens não podem se sobrepor (como duas pessoas falando simultaneamente), adjacência de turnos rompida.

As primeiras características citadas pela autora referem-se àqueles intercâmbios através de recursos que exigem que se envie as mensagens "por completo", como no ICQ, e-mail, fórum, etc. Ou seja, é diferente do encontro face-aface ou da interação através de serviços como o Talk ${ }^{6}$ ou $\mathrm{Skype}^{7}$, em que se pode responder enquanto o outro está falando. No que toca ao rompimento da adjacência dos turnos, em fóruns e salas de bate-papo, por exemplo, as mensagens são publicadas no sistema na ordem em que chegam, ou seja, não necessariamente abaixo da mensagem que estão respondendo ${ }^{8}$. No caso da interação assíncrona, isso é ainda mais freqüente, já que os participantes do debate acessam o recurso em momentos diferentes. E devido a certos atrasos de transmissão (o chamado "lag"), uma pergunta pode até mesmo aparecer depois de uma resposta a ela, tanto em processos síncronos (IRC) como assíncronos (lista de discussão).

Estudos em coerêcia conversacional, um importante aspecto da Análise da Conversação, buscam avaliar a conexão entre falas adjacentes. Herring (1999), por outro lado, aponta que as violações na coerência seqüencial são a regra e não a excessão na comunicação mediada por computador. Mensagens contectadas entre si, são com frequência separadas por muitas outras intervenientes. Conversações online em salas de bate-papo podem parecer caóticas para iniciantes. Porém, dois participantes podem estar trocando mensagens entre si, sem mesmo levar em conta o que os outros estão dizendo. Podem também trocar idéias com diversas pessoas, falando sobre diversos assuntos diferentes. Nesses casos, é comum iniciar-se a mensagem com o nome da pessoa com quem se quer falar. Uma estratégia utilizada

\footnotetext{
${ }^{6}$ Serviço de conversação escrita, bastante popular antes da chegada da Web, em que a tela era dividida em duas metades, cada uma delas sendo ocupada por um interagente. A conversação ocorria então de forma síncrona, cada pareceiro podendo ver a digitação do outro em tempo real.

7 http://www.skype.org/

${ }^{8}$ Este artigo pretende observar se estas características também ocorrem nas conversações em blogs.
} 
para contextualizar a resposta em listas de discussão ou em fóruns é o uso de citação direta, copiando trechos de mensagem anterior. De qualquer forma, um mesmo email pode conter respostas para diversas mensagens anteriores. Todos esses exemplos demonstram que na comunicação mediada por computador a coerência conversacional pode ser mantida, apesar da quebra das seqüências e regras, que seriam observadas em um encontro face-a-face. De qualquer forma, certas normas e convenções (como citações e vocativos) ainda são compartilhadas, mas adaptadas às especificidades do meio informático.

\section{A conversação em blogs}

Apesar dos blogs serem normalmente referidos como ferramentas que simplificam a publicação online, Efimova e de Moor (2005) afirma que eles tem facilitado a conversação na Internet. Os autores definem conversações em blogs como "a series of interrelated (interlinked) weblog posts and comments on a specific topic, usually not planned, but emerging spontaneously9" (p. 1). A conversação em blogs ocorre quando um post ${ }^{10}$ motiva ofeedback de outros internautas.

Marlow (2004, p. 1) entende também que os blogs, além de uma grande inovação como sistema pessoal de publicação, motivam uma nova forma de interação social. Para Marlow, os autores passam a se conhecer de maneira informal a partir da constante leitura, escrita e referenciação em seus blogs.

Os programas de blogs hoje oferecem uma série de recursos que facilitam a conversação em blogs, mesmo aquelas que percorrem blogs/lugar diferentes, como comentários, permalink, trackback e blogroll.

A ferramenta de comentários é um dos recursos mais importantes para o desenvolvimento de conversações em blogs. Normalmente, abaixo de cada post é exibido um link que abre a janela de comentários. Esse link apresenta o número de comentários já publicados até o momento, o que facilita o acompanhamento da

\footnotetext{
9 Tradução dos autores: uma série interligada de posts de blogs e comentários sobre um tópico específico, normalmente de forma não planejada, mas emergindo espontaneamente.

10 O post é a menor unidade do texto de um blog. Trata-se de um bloco de texto, contendo pelo menos um parágrafo, e que normalmente traz informações sobre quem e quando o escreveu. Pode também trazer o título de uma categoria a que o post pertence, além de trackback e permalink, que serão discutidos em breve.
} 
conversação. Na janela que se abre, os comentários são apresentados em ordem cronológica, acompanhados da hora de publicação e de seu autor. Na janela de comentários, o debate prossegue como em um fórum, conforme aponta Marlow (2004), oferecendo também ao blogueiro a percepção sobre o impacto de seus posts.

Normalmente a conversação se desenvolve a partir das reações ao post original. Contudo, nada impede que a conversa tome outros rumos ou mesmo que se publique comentários fora de contexto. Vários assuntos podem ser discutidos ao mesmo tempo, mesmo aqueles sem nenhuma relação com o post original. Uma conversação pode ainda ir além dos comentários de um certo blog, espalhando-se e ampliando-se através de posts em outros blogs e de seus respectivos comentários. É como se a conversação "escorresse" por entre diversos blogs. Percebe-se aí o caráter "viral" da conversação mediada por blogs.

Se alguém prefere escrever em outro blog sobre um tema surgido em um texto alheio, ele pode referenciar o post que deu origem a sua reflexão. Porém, pelo caráter dinâmico dos blogs, um link para a página inicial (home) de outro blog pode não ajudar os internautas, pois aquele post que originou o prolongamento alhures do tópico já não se encontra mais na home, e sim em alguma página de arquivo do blog (normalmente listadas por intervalo de data em uma coluna lateral). Os permalinks visam resolver tal problema de interconexão. Através desse recurso, cada post tem seu próprio link, que aponta diretamente para ele (e não para a página inicial do blog), apresentando-o no topo da janela do browser. Para o blogueiro que referencia um post de outro blog através de permalink, este serve como uma forma de contribuir com o leitor, indicando de onde emergem as idéias escritas no post, e com o autor do post para qual o permalink aponta, pois a utilização desse recurso confere o devido crédito às idéias que estão sendo comentadas e lhe direciona novos visitantes. Esse recurso também permite ao blogueiro não alongar-se no resumo das idéias do post alheio que ele passa a comentar localmente (e não na janela de comentários daquele outro blog).

Enquanto o permalink é um apontador que conecta um post ou comentário de terceiro ao post original em outro blog, o trackback é acionado no próprio post que se quer comentar. Ele serve como um rastro, um aviso de que um blog de terceiro está comentando aquele post, e oferece um link direto para lá. Assim, o blogueiro e 
seus visitantes podem conhecer a repercussão que aquele post está tendo em outros lugares.

O blogroll, por sua vez, é o recurso mais antigo, já que praticamente surge junto com os blogs. De certa forma, até confunde-se com os primeiros blogs, pois muitos deles consistiam em listas de links para outros sites. Porém, atualmente os blogueiros costumam utilizar essa barra lateral para listar principalmente outros blogs ou sites que costumam visitar. Para o blogueiro, o blogroll pode servir como uma lista de favoritos, facilitando sua visita a tais páginas. Para o visitante/participante, esse recurso pode servir como uma lista de recomendações. Blanchard (2004, p. 9) afirma que os blogrolls que conectam blogs com grande fluxo de comentários e que compartilham os mesmos leitores podem contribuir para a formação de uma comunidade. "If this interlinking of blogs develops around particular topics, it is possible that a sense of community may develop and be shared between these interactive blogs".

Finalmente, é importante lembrar que a conversação pode também estender-se e ramificar-se através de outros meios (digitais ou não). Por exemplo, um debate em andamento em um blog pode prosseguir através de e-mails entre certos interagentes (que podem estar ou não escrevendo nos comentários), de ligações telefônicas ou mesmo em uma conversa de bar. Nestes casos, a conversação em grupo que iniciou no blog pode motivar muitas outras conversações em diferentes lugares e mesmo entre diferentes pessoas.

\section{O estudo de conversações em comunidades de blogs}

O estudo de conversações em weblogs encontra alguns problemas, conforme Efimova e de Moor (2005), que não são enfrentados por análises de conversações mediadas por outras ferramentas digitais, como em listas de discussão. São elas: a) natureza distribuída e fragmentada das conversações, pois elas podem se distribuir por diversos blogs; b) falta de links bidirecionais, pois normalmente um post pode linkar para o post anterior, ao qual ele se refere, mas o apontamento inverso não ocorre $^{11}$; c) falta de tecnologias de rastreamento, isto é, existem mecanismos de busca para procurar o uso de palavras-chave, citação de URLs e links para certos posts, mas

\footnotetext{
${ }^{11}$ Esse problema pode ser solucionado pelos trackbacks.
} 
não uma forma de se rastrear uma série de argumentos interligados. Por outro lado, uma série de fatores facilitam o estudo de conversações mediadas por blogs. Primeiramente, o caráter público dos blogs e de seus registros dos posts (que revelam interesses particulares) e de links para outros blogs (que indicam relações e influências entre os participantes). Além disso, alguns recursos tecnológicos também viabilizam tais investigações, como as janelas de comentários, os agregadores de notícias, e as ferramentas de busca voltadas especificamente para blogs ${ }^{12}$. Trackbacks, permalinks e blogrolls, por exemplo, permitem a análise da interconexão entre blogs. Efimova e de Moor apontam inclusive que o uso ou não de um recurso tecnológico influencia o conteúdo de um blog e, portanto, a dinâmica social em torno dele.

Os recursos discutidos na seção anterior, podem também contribuir para a identificação de clusters de blogs, conforme Efimova e de Moor (2005). Se a conversação em blogs não se desenvolve em um espaço neutro, mas sim entre espaços pessoais distribuídos, conectados por um tecido complexo de relações, o autores defendem que o estudo desse fenômeno deve levar em conta o contexto sócio-técnico. Ou seja, é preciso estudar o ritmo de atividades no decorrer do tempo, a escolha dos meios (post, comentários, e outros recursos de comunicação) e as práticas de "linkagem".

A partir do estudo empírico de uma conversação que se espalhou por diversos blogs, Efimova e de Moor (2005) encontraram três fenômenos que caracterizam a conversação em blogs: linkagem como cola conversacional, conversações tangenciais e conversação com o self e com os outros. O primeiro deles refere-se ao uso de links, trackbacks e citações diretas que interconectam os blogs através dos quais se espalha a conversação. Para os autores, essas práticas funcionam como uma cola que une a conversação. Sem esses recursos, a conversa perde sua conexão "física", mesmo que os posts espalhados em diferentes blogs estejam conectados logicamente. Enquanto um debate em um fórum ocorre em um mesmo espaço compartilhado, a conversação espalhada entre blogs é conectada através do esforço dos participantes. A segunda característica citada pelos autores refere-se à capacidade dos blogs em viabilizar conversações tangenciais. Isto é, além da

${ }^{12}$ Como o Blogdex (http://blogdex.net/). 
conversação "global" desenvolvida entre blogs, existem outras "locais", através dos comentários vinculados a posts. As conversações também tendem a dividir-se em subtópicos ${ }^{13}$, que são mantidas simultaneamente. Além disso, a interação não resume-se necessariamente à mediação dos blogs, já que os interagentes utilizam também outros meios para conversarem. Efimova e de Moor concluem que além de um espaço para a conversação com outros (possibilidade oferecida por diversos serviços na Internet), os blogs permitem a “conversação com o próprio self”. Com isso se referem a uma narrativa pessoal que tem impacto na articulação e organização do pensamento próprio.

Já Marlow (2004) vai dedicar seu estudo sobre conversação em blogs ao estudo dos links entre eles, através da análise de redes sociais (Social Network Analysis - SNA). Por outro lado, quer-se aqui defender que a conversação não pode ser estudada apenas através de um estudo quantitativo de links. E mesmo a avaliação da autoridade e influência de um blog (foco de Marlow) não pode resumir-se ao estudo da estrutura hipertextual de blogs (a interconexão entre eles), sendo preciso também levar em conta o quê se diz nesses textos.

A conversação é um processo que acontece no tempo. Sua evolução não pode ser pré-determinada. Seu encaminhamento é definido entre os interlocutores apenas durante a interação. Ou seja, não se pode dizer que se o blog X mantém um link para o blog Y em seu blogroll, e vice-versa, os respectivos blogueiros estejam conversando entre si. Vale lembrar que alguns blogueiros promovem si a chamada permuta de links. Baseando-se no trabalho de Walker (2002) sobre a economia de links na Web, Primo e Recuero (2004) explicam aquele procedimento: "um 'blogueiro' recebe na janela de comentários a informação de que o visitante linkou aquela página em seu próprio blog e solicita a mesma cortesia em retorno". Ou seja, a intenção de ambos é aumentar o fluxo de visitas em seus blogs, a partir do aumento de links que apontam para eles. Logo, um link em um blogroll não garante que dois blogueiros tenham um relacionamento entre si. Enfim, deve-se compreender que a conversação se dá entre internautas e não entre blogs.

${ }_{13}$ Ou mesmo em diferentes línguas, dependendo do caso e do perfil dos participantes. 


\section{A conversação na comunidade de blogs insanus}

Para o estudo da conversação em blogs, este trabalho investigou as interações conversacionais na comunidade insanus (http://www.insanus.org). A escolha justifica-se pela organização do grupo, intensa publicação de posts, interação contínua entre os participantes, e pela comunidade já ter obtido reconhecimento na mídia (nos jornais Zero Hora e Folha de São Paulo, por exemplo). Outro fator importante para essa escolha é a facilidade de entrevistar os blogueiros, pois quase todos também residem em Porto Alegre, como os autores deste trabalho.

A comunidade de blogs insanus é uma iniciativa de Gabriel Pillar (21 anos), estudante de jornalismo da Universidade Federal do Rio Grande do Sul (UFRGS). Inicialmente o domínio (http://www.insanus.org) daria suporte a um fanzine que lançaria com colegas, no início da faculdade, em 2002. Porém, o projeto acabou sendo esquecido. Mais de um ano depois, ele resolveu que usaria o domínio que havia comprado naquela época para hospedar o próprio blog, e logo convenceu Vanessa Wozcniaki a juntar-se a ele. Assim nascia o insanus como um agrupamento de blogs. Alguns amigos transferiram seus blogs que estavam hospedados em outros servidores, outros lá começaram o seu primeiro blog. Hoje, no momento de escrita deste artigo, o insanus conta com 16 blogs individuais ${ }^{14}$, três coletivos ${ }^{15}$ e um "institucional"16. Entre outras funcionalidades, os associados da comunidade podem hoje optar por utilizar ou não ferramentas como janelas de comentários, permalink e trackback.

Para este estudo, todos os posts e respectivos comentários dos blogs do insanus, no período de 22 de março à 22 de abril de 2005, foram copiados e

${ }_{14}$ Os blogs individuais são: Big Muff, de Bruno Galera; Tripa Nelas Tudo / Cardoso, de André "Cardoso" Czarnobai; Dois Uísque, de Diego "Bituca" Salgado; Filisteu, de Francisco Araujo da Costa; Entre os Cátaros, de Marcelo Firpo; Gabbinete Dentário, de Alexandre Rodrigues e Luzia Lindenbaum; Narrativas de Niil, de Hermano Freitas; Martelada, de Marcelo Träsel; A Vida Mata A Pau, de Eduardo Menezes; Mujique, de Saulo Szinkaruk; Offset 75, de Carol Bensimon; Samjaquimsatva, de Renato Parada; Rancho Carne, de Daniel Galera; Sinye, de Vanessa Wozcniaki; Vertigo, de Gabriel Pillar; Viper Rum, de Caroline Andreis.

${ }^{15}$ A Nova Corja, de Walter Valdevino Oliveira Silva, Rodrigo Alvares e Carlos Bencke, Cove (que inicialmente apenas vendia camisetas), de Elvis Branchini, Eduardo Menezes e Antenor Savoldi, Conversas Furtadas (que transcreve fragmentos de conversas escutadas nas ruas, elevadores, etc.), escrito por todos os participantes do insanus, com contribuições de outros internautas.

${ }^{16} \mathrm{O}$ Metablog é um blog escrito por Gabriel Pillar sobre o próprio insanus. 
analisados. Dessa amostra, uma conversação que envolveu vários blogueiros do insanus e outros comentaristas foi selecionada, e será aqui discutida.

Durante o mês de maio de 2005, foram enviados questionários por e-mail com perguntas abertas para os participantes da comunidade, para que falassem sobre seus próprios blogs. Do universo de dezesseis blogs individuais, 14 responderam ao questionário, além de um colaborador de um blog coletivo: Walter Valdevino Oliveira Silva, do A Nova Corja. No dia 7 de junho de 2005, os participantes foram convidados a participar de um grupo foco, realizado no Laboratório de Interação Mediada Por Computador (LIMC) da UFRGS. Participaram da entrevista: Gabriel Pillar, Carolina Bensimon, Diego "Bituca” Salgado, Marcelo Trasel, Rodrigo Oliveira Alvares, Saulo Szinkaruk e Francisco Araujo da Costa.

A seguir apresenta-se alguns resultados da pesquisa, ainda parciais em virtude da dimensão máxima exigida para este artigo.

\section{Caracteríticas dos blogs estudados}

Dos blogs individuais da comunidade insanus, apenas Offset75 e Dois Uísque não possuem a ferramenta trackback, e apenas Rancho Carne não oferece o recurso de comentários. Daniel Galera, do Rancho Carne, explica que, quando ainda o hospedava em outro servidor, "acabei eliminando a opção de comentários em algum momento, por irritação ou desconforto em relação ao que era comentado", e quando se mudou para o insanus, decidiu mantê-lo assim. Offset 75 esteve com a opção de comentários desativada durante o período de 22 de março a 25 de abril de 2005. Durante a entrevista em grupo, Bensimon contou que resolveu tirar os comentários por sentir-se incomodada com as observações do colega Hermano Freitas, do blog Narrativas de Niil. Porém, resolveu reativar o recurso, pois sem ele "dá uma sensação de que ninguém está lendo", conforme comentou no grupo foco.

Nas entrevistas feitas com os blogueiros por e-mail, alguns declararam que não possuem permalink ou que nem sabem do que se trata a ferramenta. Apesar desse desconhecimento, todos os blogs do insanus possuem a ferramenta.

Na tabela a seguir, pode-se observar o uso e as opiniões dos blogueiros a respeito das ferramentas trackback, permalink, comentários e blogroll. Algumas 
respostas na tabela apresentam mais de duas marcações de referência (conforme a legenda), em virtude de respostas dúbias ao questionário. Por exemplo, Daniel Galera, do Rancho Carne, afirmou: "Não tenho certeza do que é blogroll, mas se é a lista de blogs que indico no meu template, sim, tenho um blogroll”. Esta afirmação, mais a de que lê alguns dos blogs listados no seu blogroll diariamente e outros semanalmente, geraram a classificação "XSE?”.

\begin{tabular}{|c|c|c|c|c|c|}
\hline & & 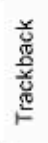 & 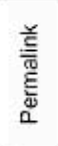 & 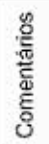 & $\begin{array}{l}\overline{\bar{g}} \\
\frac{\mathrm{g}}{\overline{0}}\end{array}$ \\
\hline Big Muff & V & $\mathrm{X} 1$ & $\mathrm{x} 1$ & $\mathrm{X} 1$ & XS \\
\hline Tripa Nelas Tudo & V & $\times 1$ & $\mathrm{x} 1$ & $\mathrm{X} 1$ & XEN \\
\hline Dois Uisque & V & $\mathrm{O} 2$ & $X ? 2$ & $\mathrm{X} 1$ & $X E$ \\
\hline Filisteu & $\mathrm{V}$ & $\mathrm{X} 1$ & $\mathrm{X} 1$ & $\mathrm{X} 1$ & XEN \\
\hline Entre os Cătaros & V & $\mathrm{X} 2$ & $\mathrm{X} 2$ & $\mathrm{X} 1$ & XS \\
\hline Gabinete Dentário & & $x$ & $x$ & $x$ & $x$ \\
\hline Narrativas de Nlil & V & $\times 2$ & $\mathrm{X} 2$ & $\mathrm{X} 1$ & XS? \\
\hline Martelada & $\mathrm{V}$ & $\mathrm{X} 2$ & $\mathrm{X} 1$ & $\mathrm{X} 1$ & $\mathrm{XN}$ \\
\hline A Vida Mata A Pau & $\mathrm{V}$ & $\mathrm{X} 1$ & $\mathrm{X}$ ? & $\mathrm{X} 1$ & 0 \\
\hline Mujique & $\mathrm{V}$ & $\mathrm{x} 1$ & $x ?$ & $\mathrm{X} 1$ & XS \\
\hline Offset 75 & & 0 & $\mathrm{x}$ & $\mathrm{x}$ & 0 \\
\hline Samjaquimsatva & V & $\mathrm{x} 2$ & $\times 2$ & $\mathrm{X} 1$ & xS \\
\hline Rancho Carne & $\mathrm{V}$ & $\mathrm{x} 1$ & $\mathrm{x} 1$ & 0 & XSE? \\
\hline Sinye & $\mathrm{v}$ & $\mathrm{X} 2$ & $\mathrm{x} 1$ & $\mathrm{X} 1$ & $\mathrm{XE}$ \\
\hline Vertigo & $\mathrm{V}$ & $\mathrm{x} 1$ & $\mathrm{X} 1$ & $\mathrm{X} 1$ & $\mathrm{XL}$ \\
\hline Viper Rum & V & $\mathrm{x} 1$ & $\mathrm{X}$ ? & $\mathrm{X} 1$ & $\mathrm{XN}$ \\
\hline A Nova Coria - Walter & V & $\mathrm{X} 2$ & $\mathrm{X} 1$ & $\mathrm{X} 1$ & XS \\
\hline
\end{tabular}

\begin{tabular}{|l|}
\hline Legenda \\
\hline$X=$ Sim \\
\hline$O=$ Não \\
\hline$?=$ Não conhece ou respondeu errado \\
\hline$V=$ Respondeu ao questionário \\
\hline$S=$ Lẻ Sempre \\
\hline$N=$ Não Lê \\
\hline$E=$ Lẽ esporadicamente \\
\hline 1 = Acha importante \\
\hline 2 = Não acha importante \\
\hline
\end{tabular}

Quando questionados no grupo foco se consideravam seus blogs um "diário íntimo", um forte debate teve início entre os blogueiros. Com excessão de Carol Bensimon, que reconhece que seu blog volta-se para relatos sobre fatos de sua vida, o restante dos participantes não demonstrou sentir-se confortável com aquele rótulo, mesmo admitindo eventualmente escrever sobre fatos do seu cotidiano. Francisco da Costa, por outro lado, negou o termo diário declarando que "eu não sou o assunto do meu blog”. A palavra íntimo, para os entrevistados, não cabe ser usada para se referir a uma página visitada diariamente por centenas de pessoas. Segundo Saulo Szinkaruk, "Inclui alguns acontecimentos vividos por mim sim, mas não é íntimo". Bruno Galera assim reagiu a questão no questionário, respondido por e-mail: "Diário íntimo, no fundo, é uma coisa secreta, de caderninho. No momento que tu coloca isso pra milhares de pessoas, acho que 1) não é mais íntimo 2) corrompe a inocência de escrever sobre todos os acontecimentos do teu dia-a-dia. Mesmo que o blog seja 
explicitamente confessional, penso que, quando ele possui o status de público, a forma como as coisas são descritas se modificará".

\section{Conversação no insanus}

Para melhor compreender o processo de conversação em uma comunidade de blogs, esta pesquisa analisou uma conversação no insanus que percorreu diversos blogs, e envolveu não apenas os blogueiros do insanus, mas também outros internautas nas janelas de comentários. Para tanto, observou posts, comentários e o uso de permalink e trackback durante o desenvolvimento da conversação estudada. Como se viu, o grupo de blogueiros compartilha muitos interesses, mas é bastante crítico quanto aos textos dos colegas. Com frequência os participantes fazem correções aos erros ortográficos e mesmo factuais cometidos pelos participantes da comunidade. E não raro escrevem posts ou comentários em outras línguas, utilizam muita ironia ou competem por erudição. Porém, essas práticas que poderiam ser consideradas rudes em outros contextos, são bastante normais no insanus e têm inclusive um caráter lúdico. Muitas das disputas e conflitos entre eles acabam também sendo debatidos através de outros meios, como ICQ, e-mail, lista de discussão do insanus, ou mesmo em encontros presenciais, principalmente em mesas de bar, conforme relatam os participantes.

Para discutir o emaranhado do percurso da conversação entre os blogs, analisar-se-á uma conversação que parte do post que Carol Bensimon publicou em seu blog (Offset75), no dia 19 de abril de 2005 às 17:0oh ${ }^{17}$. Naquele período, o cardeal Joseph Ratzinger acabava de ser eleito Bento XVI. Carol postou uma imagem antiga do novo Papa, usando uniforme da juventude nazista, e comentou:

Não gosto da Alemanha. Às vezes eu me pego pensando como de fato os alemães de hoje veêm a Segunda Guerra (...). Meu Deus, eles SABIAM o que eu estava acontecendo, isso eu sinceramente não consigo deixar de lado, perdoe. Na minha planejada viagem pra França, pretendo pegar um trem em Paris e ir até Praga. Me entristece ter que passar pela Alemanha. Acho um desperdício. Daí agora vem esse papa, só pra confirmar que alemão é sempre de direita. Cada vez mais admiro os franceses.

${ }_{17} \mathrm{http} / / /$ www.insanus.org/offset75/arquivos/oo8274.html 
Como na época o blog de Bensimon não permitia comentários, Marcelo Träsel publicou sua resposta em um post de seu próprio blog, o Martelada, no mesmo dia, às 20:07h. O post começa com um título em alemão, sem tradução para o português: soll ich dir antworten? Na seqüência, Träsel comenta ${ }^{18}$ :

A Carol B. se pergunta ${ }^{19}$ como os alemães de hoje vêem a Segunda Guerra. Tendo passado alguns meses lá, sinto-me apto a responder. De uma maneira geral, mesmo nas novas gerações, que nada têm a ver com o nazismo, sentem-se bastante culpados. Justamente por saberem que sabiam de tudo. (...) Apesar de Hitler, os alemães são um dos povos mais tolerantes da Europa. (...) Os franceses e italianos, por exemplo, têm um ódio muito mais profundo aos súditos de Davi. De fato, os franceses entregaram todos os judeus que puderam a Hitler, depois de se renderem.

No Martelada os comentários são permitidos, e este post gerou 31 manifestações, que se dividiram em vários temas, incluindo a cobrança que Hermano fez pela referência em trackback no blog de Carol. Träsel logo respondeu que o Offset75 não utiliza o recurso.

Entre as manifestações de apoio e de repúdio, alguns comentários merecem destaque. Um interagente, utilizando o nick "Carmencita", envia um comentário todo em alemão, também sem tradução para o português: "Was wolltest du in Deutschland sehen? Ein großes Küsschen!” às 22:24. Oito minutos depois, Carmencita retorna e comenta: "Queria saber da Carol se ela se acha preconceituosa ou xenófoba. Não achei lugar para comentários no blog dela. Todo alemão é de direita? O partido do Schröder, o SPD, é de direita? Será que ela sabe em que lado do espectro está o Ariel Sharon? Vá de avião. Ou então passe pela Suíça e pela Áustria. Vá de navio até a Polônia e depois atravesse a fronteira". Outros visitantes também reagem com ironia: "não havia lido o texto da Carol. realmente, é óbvio que não é todo alemão que é de direita. da mesma forma que nem todo judeu é que nem o Sharon, etc. mas essa não é a questão, really. marlon em 19.04.2005 às 22:43”

O assunto se divide quando Carmencita coloca mais um comentário corrigindo a frase em alemão publicada por Träsel: "Mercelinho, lieber Freund! Não tenho intenção de soar pedante, mas: Soll ich DIR antworten? Dativo, querido. Um

\footnotetext{
$18 \mathrm{http}$ //www.insanus.org/martelada/archives/oo8286.html

19 Clicando-se nessas palavras, um permalink leva o leitor para o post de Carol: http://www.insanus.org/offset75/arquivos/oo8274.html
} 
grande beijinho! Carmencita, Die Lehrerin em 19.04.2005 às 22:56" A partir desse ponto, alguns comentários passam a discutir a dificuldade de aprender alemão, outros continuam a se referir ao posts de Carol e Marcelo e um terceiro assunto surge após Carmencita elogiar o volume de interações: “Assim é que é bom! Os blogs estão em geral se tornando locais de clipping eletrônico. Ah! E ninguém comentou sobre as salsichas...Carmencita em 19.04.2005 às 23:27”. Além de alguns comentários subseqüentes sobre salsichas, segue-se também algumas trocas entre Marlon e Mojo sobre humanismo, a partir de um comentário anterior de Träsel sobre Hitler e totalitarismo que menciona a figura do "bom selvagem".

Nesse ínterim, Bensimon descobre que está sendo comentada no Martelada. Ela lê o que já foi dito, mas opta por não responder na mesma janela. Faz um novo post no seu blog, na quarta-feira, 20 de abril às 14:20h, mas deixa um trackback avisando os visitantes do Martelada de que o Offset75 fez referência a ele.

Acréscimos a fazer ao post da Alemanha e aos comentários do postresposta ${ }^{20}$ do Träsel. Primeiro, isso aqui não é uma monografia, tá mais é pra CONVERSA DE BAR. Portanto, se digo "alemão é sempre de direita", não leve tão a sério. A Carol Andreis disse no blog dela que alemães não têm sentimento ${ }^{21}$, bem, também é apenas uma generalização (...)"

No novo post, Carol Bensimon busca apoio no post de Caroline Andreis no Viper Rum, em 19 de abril de 2005, em que ela escreve: “Alemão - Só digo uma coisa sobre esse novo papa: alemães não têm sentimento. Não sabem se expressar. A única coisa boa que fazem é misturar doce com salgado. E isso os africanos fazem de forma mais forte e refrescante". O Viper Rum admite comentários, e recebe 21 reações a esse post. Quando alguns visitantes contestam Andreis, ela explica a intenção do post e desenvolve a idéia na janela de comentários, cujo texto torna-se maior do que o próprio post ${ }^{22}$.

As reações na janela de comentários do Viper Rum dedicam-se, em sua maioria, a discutir se os alemães são frios ou não, com exceção apenas do comentário de Bensimon: "exato. gracias. teu post abriu caminho pra um meu". Outra excessão é

\footnotetext{
${ }_{20}$ Permalink para o referido post:http://www.insanus.org/martelada/archives/oo8286.html ${ }_{21}$ Permalink para o referido post:http://www.insanus.org/viperrum/archives/oo8269.html $22 \mathrm{O}$ post original teve 218 caracteres e o comentário da mesma autora, 943 caracteres.
} 
um dos comentários de Mojo, no qual ele avisa que o seu teclado está com problemas e que pode gerar alguns erros de digitação nos seus comentários.

Enquanto isso, os comentários na janela do Martelada continuam. Carmencita nota o trackback e manda um recado para Bensimon: "Está bem, querida! Já que você esclareceu o seu pensamento, não vou mais usar 'preconceituosa' e ‘xenófoba'. A propósito, você é ‘maria-vai-com-as-outras'?”.

Enfim, os seguintes temas ocupam a mesma janela de comentários de Martelada: se os alemães se sentem culpados pelo holocausto; se salsichas alemãs são as melhores; dificuldades no aprendizado da língua alemã; ter ou não ter um blog; a boa memória de Hermano; por que aquele post curto gerou mais comentários do que o post anterior, em que Träsel relatava sua pesquisa sobre as biografias dos outros papas de nome Bento; a erudição de Mojo.

A partir desse acompanhamento, foi possível observar algumas das características da conversação mediada por computador citadas por Herring (1999). Os interagentes puderam manter a conversação na janela de comentários apesar da grande variedade de assuntos em discussão e sem que houvesse uma estrita adjacência de turnos. Ou seja, respostas a comentários anteriores eram frequentemente separadas por falas sobre outros assuntos sendo discutidos. Mesmo assim, tal quebra sequencial não pareceu prejudicar os debates em andamento.

Pode-se observar uma grande variedade nas características de cada comentário. Eles variaram em tamanho, sendo alguns muito curtos enquanto outros bastante extensos, e abordagem, podendo ser tanto irônicos e superficiais quanto bem argumentados e com citações. Alguns interagentes preferiram enviar mais de um comentário em sequência, enquanto outros responderam a diversas pessoas em um mesmo post, fazendo uso de vocativos para organizar a fala (outra característica da conversação textual mediada por computador citada por Herring).

Durante esta análise detectou-se um traço bastante peculiar em blogs: a conversação que "escorre" por entre diversos blogs e posts. Conforme o relato anterior, a interação analisada percorreu 3 blogs e tratou de vários posts (anteriores ou em outros lugares). Com a falta dos recursos de comentários e trackback no blog Offset75, reclamada por alguns participantes pois facilitam a costura da conversação, 
o debate ocorreu no blog Martelada. Carol Bensimon, contudo, usou outro post em seu blog para responder aos comentários que vinham sendo feitos no Martelada, mas fazendo uso do trackback para avisar que o post de Träsel e respectivos comentários estavam sendo lá referenciados. Como muitos dos interagentes acompanham vários blogs da comunidade insanus, a participação nessa conversação "distribuída" e fragmentada não foi prejudicada.

\section{Considerações finais}

Este trabalho procurou ir além da noção do blog como diário íntimo, como celebração do ego no ciberespaço. Com se pôde observar na comunidade de blogs insanus, existem blogs que têm mais de um blogueiro (aquele que tem acesso por senha para publicação de posts na região principal do blog). Além de blogs coletivos, pode-se afirmar que os blogs que permitem que outros internautas publiquem comentários convertem-se em hipertextos cooperativos (Primo, 2002): "todos os envolvidos compartilham a invenção do texto comum, à medida que exercem e recebem impacto do grupo, do relacionamento que constróem e do próprio produto criativo em andamento"(Primo e Recuero, 2003, p. 2). Nesse sentido, pode-se até dizer que um blog não é escrito apenas pelo blogueiro responsável, já que muitos são os interagentes que participam da escrita do blog como um todo (já que os comentários fazem parte do blog).

As conversações podem resumir-se a um blog apenas, mas também extravasar essa fronteira, espalhando-se por posts e comentários em outros blogs. Recursos como trackback e permalink contribuem para a costura dessa conversação distribuída, facilitando o acompanhamento dos interagentes.

Vale também destacar que em conversações em blogs as falas em uma janela de comentários não tratam necessariamente do post a que ela se vincula. Ou seja, um comentador pode discutir um post anterior ou mesmo posterior. E, por vezes, um post antigo pode receber novos comentários e motivar novo debate mesmo que ele tenha sido publicado há dias ou meses ${ }^{23}$.

\footnotetext{
23 Um post pode ser encontrado através de um mecanismo de busca ou nos arquivos do blog (recurso que lista e organiza posts de semanas e meses anteriores).
} 
Tendo em vista que as interações conversacionais aqui relatadas são criadas e mantidas pelos participantes do processo, tendo um impacto recursivo sobre eles e sobre a própria definição dos relacionamentos entre os interagentes, defende-se que elas configuram uma interação mútua (Primo, 2003). Como a negociação e disputa de sentidos acompanha todo o desenrolar da interação, repercutindo na evolução da conversação, esse processo ultrapassa a mera interação reativa, limitada ao apontar/clicar.

Por outro lado, apesar do tom irônico e mesmo crítico dos intercâmbios aqui relatados, pode-se observar um interesse lúdico no debate, cujo fim primeiro é manter o prosseguimento da conversação. O sucesso desse objetivo pode ser reconhecido no retorno freqüente dos internautas aos blogs e comentários. Além disso, o uso de permalinks, trackbacks e blogrolls também demonstra o pacto dos participantes em aproximar as interações localizadas neste ou naquele blog.

Sendo assim, confirmou-se na comunidade insanus as características de conversação em blogs citadas por Efimova e de Moor (2005): linkagem como cola conversacional, conversações tangenciais, e conversação com o self e com outros. Observou-se que os blogs envolvidos na conversação apontaram links uns para os outros no textos dos posts. Além do tema principal, várias conversas se desenvolveram em paralelo sem prejudicar a compreensão e participação no debate. Como relatado, esta conversação distribuída teve início com uma conversação com o self (a reflexão de Bensimon sobre os alemães e de Träsel sobre esse post), que acabou motivando uma conversação com outros na janela de comentários do Martelada e na resposta de Bensimon em novo post no Offset75 ${ }^{24}$.

24 Os autores deste trabalho querem agradecer Paula Quintas, por seu trabalho como bolsista do projeto em sua primeira fase, e aos blogueiros do insanus, por sua disposição em oferecer todos os dados necessários para a realização desta pesquisa. 


\section{Referências bibliográficas}

CHARAUDEAU, Pratick; MAINGUENEAU, Dominique. Dicionário de análise do discurso. São Paulo: Contexto, 2004.

EFIMOVA, Lilia; HENDRICK, Stephanie. In search for a virtual settlement: an exploration of weblog community boundaries. In: Communities \& Technologies'05, 2005. Anais.

EFIMOVA, Lilia; MOOR, Aldo de. Beyond personal webpublishing: an exploratory study of conversational blogging practices. In: Thirtyeighth Hawaii International Conference on System Sciences, 2005, Havaí. Anais... Havaí, 3-6 Janeiro de 2005.

GOFFMAN, Erving. Replies and responses. In: GOFFMAN, E. (Ed.). Forms of talk. Filadélfia: University of Pennsylvania, 1981.

HERRING, Susan C. Interactional Coherence in CMC. In: Thirty-second Hawaii International Conference on System Sciences, 1999, Havaí. Anais... Havaí, 1999.

MARCUSCHI, Luiz Antônio. Análise da conversação. 5. ed. São Paulo: Ática, 2001. (Princípios, 82).

MARLOW, Cameron. Audience, structure and authority in the weblog. In: International Communication Association Conference, 2004, New Orleans, LA. Anais... New Orleans, LA, Maio 2004.

PRIMO, Alex Fernando Teixeira. Quão interativo é o hipertexto? Da interface potencial à escrita coletiva. In: COMPÓS 2002 - ENCONTRO DA ASSOCIAÇÃO NACIONAL DOS PROGRAMAS DE PÓS-GRADUAÇÃO EM COMUNICAÇÃO, 11, 2002, Rio de Janeiro. Anais... Rio de Janeiro, 2002. Disponível em:<http://www.pesquisando.atravesda.net/quaum_interativo_hipertexto.pdf $>$.

PRIMO, Alex Fernando Teixeira; RECUERO, Raquel da Cunha. Hipertexto Cooperativo: Uma Análise da Escrita Coletiva a partir dos Blogs e da Wikipédia. In: VII Seminário Internacional da Comunicação, 2003, Porto Alegre. Anais... Porto Alegre, 2003. Disponível em:<http://www.pesquisando.atravesda.net/hipertexto_cooperativo.pdf $>$.

PRIMO, Alex Fernando Teixeira. Enfoques e desfoques no estudo da interação mediada por computador. In: Intercom 2003 - XXVI Congresso Brasileiro de Ciências da Comunicação, 2003, Belo Horizonte. Anais... Belo Horizonte. Disponível em:<http://www.pesquisando.atravesda.net/enfoques_desfoques.pdf $>$.

PRIMO, Alex Fernando Teixeira; RECUERO, Raquel da Cunha. Co-links: proposta de uma nova tecnologia para a escrita coletiva de links 
multidirecionais. Revista Fronteiras: estudos midiáticos, v. VI, n. $1,2004$.

SIMMEL, Georg. Culture of interaction. In: FRISBY, D.; M. FEATHERSTONE (Eds.). Simmel on culture. Londres: Sage, 2000.

WALKER, J. Links and power: the political economy of linking on the Web. In: Hypertext 2002, 2002, Baltimore. Anais... Baltimore: ACM Press, 2002.

WEI, Carolyn. Formation of norms in a blog community. 2004.

Disponível em:

http://blog.lib.umn.edu/blogosphere/formation_of_norms.html. Acesso em 17/11/2004. 